\title{
Thoraco-laparoscopic esophagectomy: thoracic stage in prone position
}

\section{Esofagectomia vídeo-tóraco-laparoscópica com tempo torácico em posição pronada}

Carlos Bernardo Cola, tCBC-RJ',2, Flávio Duarte Sabino, TCBC-RJ'1, Carlos Eduardo Pinto, tCBC-RJ', Maria Ribeiro Morard, TCBC-RJ², Pedro Portari Fillo, TCBC-RJ², Tereza Guedes ${ }^{1}$.

\section{A B S T R A C T}

\begin{abstract}
Objective: to analyze the National Cancer Institute Abdominopelvic Division (INCA / MS/HC I) initial experience with thoraco-laparoscopic esophagectomy with thoracic stage in prone position. Methods: we studied 19 consecutive thoraco-laparoscopic esophagectomies from may 2012 to august 2014, including ten patients with squamous cells carcinoma (five of the middle third and five of the lower third) and nine cases of gastroesophageal junction adenocarcinoma (six Siewert I and three Siewert II). All procedures were initiated by the prone thoracic stage. Results: There were minimal blood loss, optimal mediastinal visualization, oncological radicality and no conversions. Surgical morbidity was $42 \%$, most being minor complications (58\% Clavien I or II), with few related to the technique. The most common complication was cervical anastomotic leak (37\%), with a low anastomotic stricture rate (two stenosis: $10.53 \%)$. We had one (5.3\%) surgical related death, due to a gastric tube's mediastinal leak, treated by open reoperation and neck diversion. The median Intensive Care Unit stay and hospital stay were two and 12 days, respectively. The mean thoracoscopic stage duration was 77 min. Thirteen patients received neoadjuvant treatment (five squamous cells carcinoma and eight gastroesophageal adenocarcinomas). The average lymph node sample had 16.4 lymph nodes per patient and 22.67 when separately analyzing patients without neoadjuvant treatment. Conclusion: the thoraco-laparoscopic approach was a safe technique in the surgical treatment of esophageal cancer, with a good lymph node sampling.
\end{abstract}

Keywords: Esophagectomy. Prone Position. Thoracoscopy. Esophageal Neoplasms.

\section{INTRODUCTION}

Eophageal cancer is currently the sixth most comEmon malignant tumor in men and the thirteenth most common in women in Brazil (INCA/MS 2014)', the squamous cell carcinoma being the most prevalent subtype (60\% of new cases), followed by adenocarcinoma $(35 \%)$, the remaining $5 \%$ composed of sarcomas, carcinosarcomas and Gastrointestinal Stromal Tumors (GISTs).

Treatment of this condition includes esophagectomy whose morbidity is high, especially when associated with thoracotomy. Due to the prohibitive complication rates, the trans-hiatal technique (without thoracotomy) was developed as a tactic to enable surgery in patients with pneumopathies and/or with a high surgical risk ${ }^{2,3}$.

Data from the literature on the thoraco-laparoscopic technique show advantages when compared with esophagectomy with thoracotomy and laparo- tomy, such as shorter operative time, lower blood loss, less postoperative pain, lower percentage of pleuropulmonary complications and reduction of hospitalization time, with faster postoperative recovery ${ }^{4-7}$. Based on these data, we started the systematic thoraco-laparoscopic technique in the abdomino-pelvic surgery section of the National Cancer Institute (INCA HC I / MS-RJ) in May 2012.

Our objective is to evaluate morbidity and lymph node sampling of thoracoscopic technique in prone position in a Brazilian public institution specializing in the treatment of cancer.

\section{METHODS}

We conducted a prospective, non-randomized, observational study from May 2012 to August 2014. We included nineteen patients with esophageal cancer, whose staging by helical tomography and/or echoendoscopy was less than or equal to T3N2M0 (sta-

1 - National Cancer Institute (INCA/MS), Abdomino-pelvic Surgery Section - Rio de Janeiro, RJ, Brazil. 2 - Federal University of the State of Rio de Janeiro (Unirio), Department of General Surgery, Postgraduate Program in Medicine (PPGMED) / Professional Master's Degree, Rio de Janeiro, RJ, Brazil. 
ge III). Ten had squamous cell carcinoma (five of medium $1 / 3$ and five of lower 1/3) and nine had adenocarcinoma of the gastro-esophageal junction (Six Siewert I - 2 to $5 \mathrm{~cm}$ above the $\mathrm{Z}$ line - and three Siewert II - 2 $\mathrm{cm}$ above or below the $Z$ line). In patients with squamous cell carcinoma of the middle $1 / 3$, we performed a radical lymph node dissection at the aorto-pulmonary window, left recurrent and upper mediastinum chains. Of the 19 patients, 13 (68.4\%) received neoadjuvant treatment, and five (50\%) of the 10 cases of squamous cell carcinoma received 50.4 Gy of radiotherapy and two cycles of chemotherapy with cisplatin or carboplatin associated with 5-fluorouracil (5FU). Eight (88.9\%) of the nine cases of adenocarcinoma of the cardia received neoadjuvant treatment, five of which received exclusive chemotherapy with four cycles of 5Fu, oxaliplatin and leucovorin (Folfox), and three received $50.4 \mathrm{~Gy}$ of radiotherapy and four cycles of Folfox. We excluded patients who were not found to be apt from the cardiovascular or respiratory point of view, or with performance status greater than or equal to two (presence of incapacitating symptoms by the European Clinical Oncology Group classification) or with oncologic stage IV.

As a comparison, we used data from our previous retrospective study on conventional esophagectomy $^{3}$. Despite the impossibility of statistical comparison, given the differences in design and sampling of the studies, the variables analyzed comparing the two studies were length of stay in the ICU, time of postoperative hospitalization and number of dissected lymph nodes.

In the group submitted to thoraco-laparoscopy, we also evaluated surgical morbidity, cervical anastomosis fistula, postoperative pneumonia and anastomotic stenosis. We also analyzed the use of neoadjuvant treatment and the difference in lymph node sampling in this group.

\section{Surgical technique}

The technique used was thoracoscopy in prone position in all cases (Figures 1 and 2), followed by laparoscopy in the abdominal time. We initiated all procedures by the thoracic time on the right with a 30-degree endoscope and three trocars (Figure 3 ). The first $10 \mathrm{~mm}$ trocar was positioned in the fifth intercostal spa- ce in the medial axillary line (endoscope), the second of $5 \mathrm{~mm}$ in the seventh intercostal space in the posterior axillary line (surgeon's left hand) and the third of $12 \mathrm{~mm}$ in the fourth intercostal space in the posterior axillary line (surgeon's right hand). We performed the thoracic procedure with the patient in ventral decubitus (prone position), orotracheal intubation with a Robert Shawtype double lumen tube, right lung exclusion, pneumothorax with carbon dioxide, and cavitary pressure of 12 $\mathrm{mmHg}$. We carried out the dissection with atraumatic forceps for manipulation of the esophagus, monopolar electrocautery and a bipolar sealer, dissecting the mediastinum, to achieve an en bloc mobilization of the esophagus with its periaesophageal lymphatic drainage chains and thoracic duct, ligating and sectioning the azygos vein (with a vascular endostapler or ligation with cotton sutures and metal clips). During mediastinal lymphadenectomy, we performed an en bloc resection of the right and left paratracheal lymph nodes, as well as the upper and lower tracheobronchial, infracarinal and periaesophageal chains, and the thoracic duct. In the cases of squamous cell carcinoma of the middle third of the esophagus, we performed the meticulous and complete dissection of the lymph nodes of the aortopulmonary window and the recurrent chains. At the end of the thoracic time, we irrigated the cavity with warm saline solution and positioned a 30 or $32-\mathrm{Fr}$ thoracic drain parallel to the esophageal resection bed (Figure 4 ), checking for pulmonary re-expansion under thoracoscopic control.

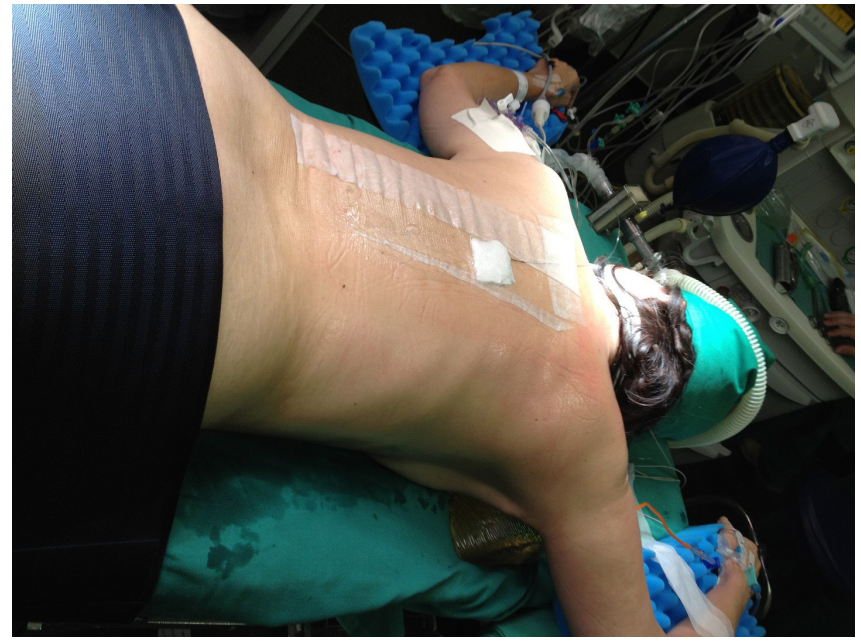

Figure 1. Prone position with cushions and restraint bands 


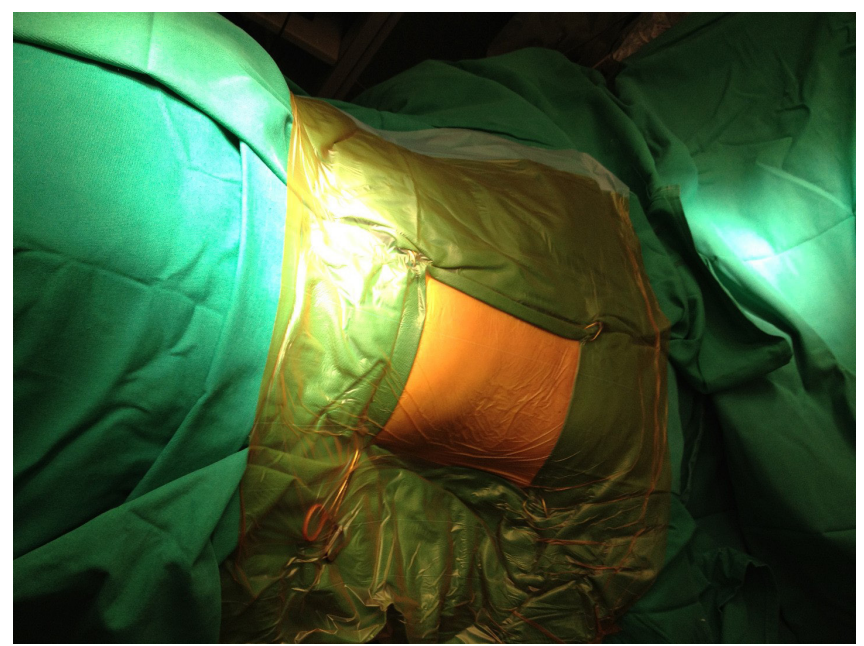

Figure 2. Placement of sterile fields.

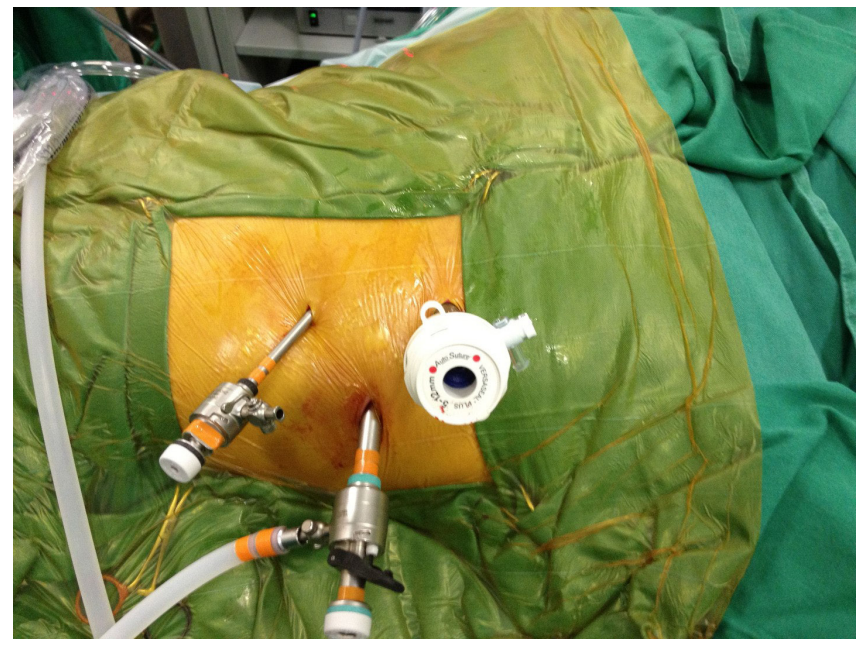

Figure 3. The three trocars in position.

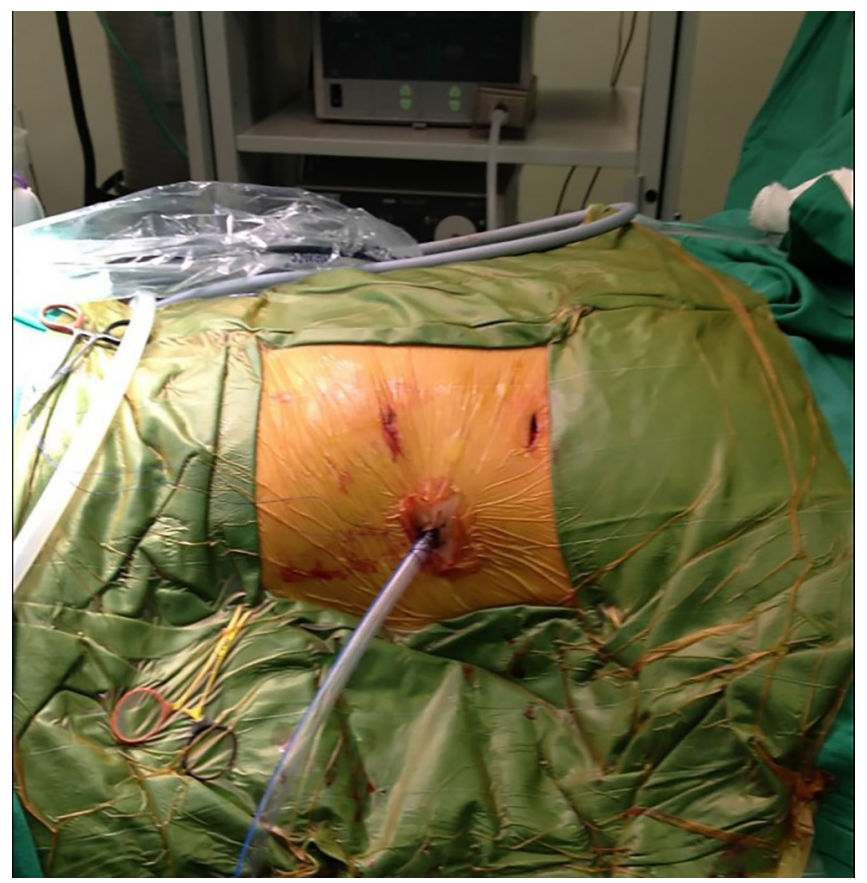

Figure 4. Thoracic drainage positioned through the endoscope port.
We then positioned the patient in dorsal decubitus, and replaced the double lumen orotracheal tube by a conventional, ventilating both lungs. We initiated the abdominal time by pneumoperitoneum through a $10 \mathrm{~mm}$ umbilical trocar (open technique), and positioned three additional trocars, two for the surgeon, one $12 \mathrm{~mm}$ on the left mammillary line above the umbilical line and one $5 \mathrm{~mm}$ on the right nipple line in the same level). The third trocar, of $5 \mathrm{~mm}$ for the first auxiliary, was introduced into the right anterior axillary line below the surgeon's trocars, thus totaling four trocars. We mobilized the stomach by the gastrocolic ligament with bipolar sealer, preserving the gastroepiploic arcade, with ligation of the left gastroepiploic, short gastric, left gastric and posterior gastric vessels.

Radical lymphadenectomy included stations 8 (common hepatic artery), 9 (celiac trunk), 7 (left gastric artery) and $11 \mathrm{p}$ (proximal splenic artery), as well as stations 1, 2 and 3. At the end of the en bloc lymphadenectomy, we broadly opened the esophageal hiatus by partially sectioning the left pillar to allow passage of the gastric tube into the mediastinum and to communicate abdominal and thoracic dissections.

The stomach remained vascularized by the right gastric and gastroepiploic vessels. At the end of abdominal time, we performed a left anterolateral cervicotomy, following the anterior border of the sternocleidomastoid muscle, opening the lining and pre-tracheal layers of the cervical fascia, isolating the cervical esophagus, with careful preservation of both recurrent laryngeal nerves. The esophagus was sectioned, its proximal end repaired by surgical sutures, and the distal one ligated with polyglactin 1 sutures, at the end of which a 24Fr Foley catheter was sutured to aid in the rise of the gastric tube.

After the esophageal release, we widened the $12 \mathrm{~mm}$ abdominal trocar wound (right hand of the surgeon) to $5 \mathrm{~cm}$, protecting the abdominal wall with a plastic cover, and removing the surgical specimen with the en bloc mediastinal and abdominal lymphadenectomies. We prepared the gastric tube outside the abdominal cavity through this minilaparotomy, using a linear $80 \mathrm{~mm}$ shear stapler with five to six blue loads, resulting in a narrow gastric tube, $3 \mathrm{~cm}$ to $3.5 \mathrm{~cm}$ wide, with reinforcement of the entire Clipping line with continuous suture of polypropylene 3.0 and addition of a piloromiotomy 
(optional).

We transposed the prepared gastric tube to the neck with aid of the Foley catheter, and made a lateral-lateral esophagogastric anastomosis with a $45 \mathrm{~mm}$ endostapler. The lower 2/3 of the cervical wound remained open to evaluate the viability of the gastric tube and to facilitate drainage in case of cervical fistulas.

\section{RESULTS}

Table 1 shows the epidemiologic characteristics of the 19 operated patients. Surgical morbidity was $42 \%$ (eight patients), the most common complication being cervical fistula (37\%), followed by pneumonia $(10.5 \%)$, with overlapping complications (Table 2 ).

Table 1. Epidemiological characteristics.

\begin{tabular}{ccc}
\hline Gender & Male: $15(79 \%)$ & Female: $4(21 \%)$ \\
\hline Mean age (years) & 59.3 & 58.5 \\
\hline Histology & Squamous cell carcinoma: & Adenocarcinoma: \\
\hline & IA: $1(52,6 \%)$ & \\
& IIA: $5(26.3 \%)$ & \\
Stage & IIB: $1(5.3 \%)$ & \\
& IIIA: $7(36.7 \%)$ & \\
& IIIB: $2(10.6 \%)$ & \\
& IIIC: $3(15.8 \%)$ & \\
& Upper $1 / 3: 0$ \\
Ledium 1/3: $5(26.3 \%)$ & \\
& Lower 1/3: $14(73.7 \%)$ \\
\hline
\end{tabular}

Table 2. Morbidity and mortality.

\begin{tabular}{cc}
\hline Complications & Patients (\%) \\
\hline Cervical Fistula & $7(36.8 \%)$ \\
Anastomotic stenosis & $2(10.5 \%)$ \\
Pneumonia/Tracheostomy & $2(10.5 \%)$ \\
Reoperation & $2(10.5 \%)$ \\
Organic Failure/Sepsis & $1(5.25 \%) *$ \\
Mediastinal Linfocele & $1(5.25 \%)$ \\
Death & $1(5.25 \%) *$ \\
\hline
\end{tabular}

* complications superimposed on a same case.

Two patients were reoperated: one for acute hiatal hernia (left colon) on the fifth postoperative day, treated by laparoscopic hiatoplasty, with discharge on the eighth postoperative day; and one due to a mediastinal fistula of the tip of the gastric tube, on the seventh postoperative day, treated by right thoracotomy and cervical shunt of the tip of the gastric tube. The patient died of multiple organ failure on the ninth postoperative day, despite intensive care, and was the only death in our series $(5.3 \%)$.

The mean lymph node sampling was 16.4 lymph nodes, with neoadjuvant treatment in $63.16 \%$ of the patients (Table 3 ). When we analyzed the cases operated without neoadjuvant treatment, we observed a mean of 22.67 lymph nodes (Table 4). The mean of metastatic lymph nodes was 1.95 per patient, 4.8 per patient in the group without neoadjuvant treatment and 0.6 in the group receiving it. 
Table 3. Neoadjuvant Treatment

\begin{tabular}{cc}
\hline No & $6(31.58 \%)$ \\
\hline & $13(68.42 \%)$ \\
Yes & QT: $5(26.32 \%)$ \\
& RT-QT: $8(42.1 \%)$ \\
\hline
\end{tabular}

Table 4. Neoadjuvant Treatment versus average lymph node sampling.

\begin{tabular}{ccc}
\hline Yes $\left(\mathrm{QT}{ }^{*}\right)$ & $\mathrm{N}=5$ & $14 \mathrm{LNs}^{* * *}$ \\
Yes $\left(\mathrm{QT}-\mathrm{RT}{ }^{* *}\right)$ & $\mathrm{N}=8$ & $9.2 \mathrm{LNs}$ \\
No & $\mathrm{N}=6$ & $22.7 \mathrm{LNs}$ \\
\hline
\end{tabular}

* QT: chemotherapy; ** RT: radiotherapy; ${ }^{* \star *}$ LNs: lymph nodes.

There was no conversion to open technique in any of the 19 cases. The mean duration of the thoracic time was 77 minutes. There was no significant blood loss. The median length of stay in the Intensive Care Center (ICU) and in the hospital were, respectively, two and twelve days. We started the enteral diet on the first postoperative day in all 19 cases.

\section{DISCUSSION}

Transthoracic esophagectomy is traditionally associated with thoracotomy morbidity and its complications, although it undeniably provides adequate exposure for mediastinal lymphadenectomy 2,3,5,6. Video-surgery has been employed to reduce this morbidity, using small intercostal incisions, with a magnified view of the mediastinal structures and better hemostasis, thanks both to the pneumothorax and to the greater delicacy in the dissection and use of modern vascular sealers. It minimizes morbidity of the thoracic time and provides a suitable pathway for complete mediastinal lymphadenectomy, reducing postoperative pain and providing a surgical specimen containing all periesophageal lymphoadiposal tissue and thoracic duct 4,9,10.

In the present study, there were few complications directly related to the video-surgical technique, demonstrating the safety of the method. Overall morbidity was $42 \%$, comparable to that of other reference centers, the majority of complications being smaller, as shown in table 5 (Clavien's classification ${ }^{11}$ ). The rate of pulmonary complications (10.5\%) was lower when compared with our previous database of conventional surgeries $(20.4 \%)^{3}$. In the specialized literature we found a wide variation in the incidence of postoperative complications, ranging from $0 \%$ (Yatabe et al. ${ }^{7}$ ) to $50 \%$ (Fabian et al. ${ }^{9}$ ). This demonstrates heterogeneity between the specialized services and the complexity of the surgical treatment of esophageal cancer. However, despite the adversities it is possible to obtain good results, superior to those of conventional surgery ${ }^{3,5}$.

Table 5. complications according to Clavien's classification.

\section{Grade I \\ 1 \\ Grade II $\quad 6$ (cervical fistulas treated conservatively)}

Grade Illa 1 (mediastinal linfocele: percutaneous drainage)

Grade IIlb 2 (reoperations, including death) *

Grade IVa

0

Grade IVb 01 (FMOS: multiple organic failure) *

Grade IVc 1 (death) *

* complications superimposed on the same case.

There was one death (mortality of $5.3 \%$ ), secondary to a mediastinal fistula at the end of the gastric tube. In the literature, we found death rates between $0 \% 9$ and $2.9 \%{ }^{6}$, in larger series than ours, making it impossible to compare directly, but showing that it is possible to significantly reduce mortality with the minimally invasive approach.

Despite the high rate of cervical fistulas (37\%), the evolution was benign in most cases, with spontaneous closure in all cases between two and seven days. Of the seven fistulas, only two evolved with stenosis and were successfully treated with endoscopic dilatation. We believe that conventional cervical time with diamond-shaped anastomosis using the linear stapler helps to reduce the incidence of anastomotic stenosis, agreeing with the literature ${ }^{12,13}$.

Regarding lymph node sampling, it is important to remember that neoadjuvant treatment considerably reduces the number of lymph nodes in the surgical specimen, especially when we associate radiotherapy and che- 
motherapy ${ }^{6,14}$. In the present study, $68.42 \%$ of patients received neoadjuvant treatment (which became the gold standard worldwide after publication of the Cross trial long-term results ${ }^{14}$ ), yet our mean lymph node sampling was 16.4 lymph nodes per patient versus 19.55 of our historical series ${ }^{6}$, in which no patient received neoadjuvant treatment. In the researched literature, only four authors ${ }^{4,5,9,12}$ reported their average lymph node sampling, the largest being of 18 lymph nodes per patient ${ }^{4}$, varying between 11.6 and 18, the majority of patients being operated without neoadjuvant treatment $t^{4,5,9,12}$, suggesting that our mean sample size was adequate. When we analyzed only the six cases operated without neoadjuvant treatment, the mean lymph node per patient was 22.67, demonstrating the ability to replicate or even improve lymphadenectomy through thoraco-laparoscopy, perhaps due to better visualization and magnification of mediastinal structures and lymphatic drainage chains $s^{4,6,9,10}$.

The median times of ICU and hospital stay were respectively two and 12 days, with a median hospital admission considerably lower than that of our conventional historical series (20 days), suggesting a clear advantage of the thoraco-laparoscopic technique, despite of the im- possibility of direct comparison due to the sample and methodological differences ${ }^{3}$.

We believe that the thoraco-laparoscopic esophagectomy should become the standard technique for the surgical treatment of esophageal and cardia cancer. We believe that with adequate patient selection, accurate oncological staging, trained surgical staff, optimized postoperative support and a larger surgical series, we can improve our results, similar to those obtained in high-volume centers that specialize in the minimally invasive treatment of esophageal cancer $2,4-6,8,9,11-14$.

Despite our small sample, we found that thoraco-laparoscopic esophagectomy is a safe, feasible and reproducible procedure in any large institution specialized in the treatment of cancer. We observed that the oncological radicality is similar or even superior to that of conventional surgery by thoracotomy and laparotomy, probably due to the better visualization and magnification of the anatomical structures. Data analysis allowed us to conclude that thoraco-laparoscopic esophagectomy with the thoracic time in prone position had acceptable morbidity and provided an oncologically adequate lymph node sampling.

\title{
R E S U M O
}

\begin{abstract}
Objetivo: analisar a experiência inicial do Serviço de Cirurgia Abdomino-Pélvica do Instituto Nacional de Câncer (INCA/MS/HC I) na esofagectomia vídeo-tóraco-laparoscópica com tempo torácico pronado. Métodos: estudo de 19 esofagectomias vídeo-tóraco-laparoscópicas realizadas de maio de 2012 a agosto de 2014, em dez pacientes portadores de carcinoma epidermoide esofágico (cinco do 1/3 médio e cinco do 1/3 inferior) e em nove portadores de adenocarcinoma da cárdia (seis Siewert I e três Siewert II). Todas as cirurgias foram iniciadas pelo tempo torácico em posição pronada, com mínima perda sanguínea, adequada visualização das estruturas mediastinais, radicalidade oncológica e sem conversões. Resultados: a morbidade cirúrgica foi de $42 \%$, sendo a maioria complicações menores (58\% Clavien I ou II). A complicação mais comum foi a fístula cervical em sete casos (37\%), com baixa incidência de estenose anastomótica (duas estenoses: 10,53\%). Houve um óbito (5,3\%), relacionado a uma fístula mediastinal do tubo gástrico, tratada com reoperação e exteriorização cervical. As medianas de permanência em Centro de Terapia Intensiva e hospitalar foram respectivamente dois e 12 dias. A mediana do tempo vídeo-toracoscópico foi de $77 \mathrm{~min}$. Treze pacientes (68.4\%) receberam tratamento neoadjuvante (cinco portadores de carcinomas epidermoides e oito de adenocarcinomas cárdia). A amostragem linfonodal média foi de 16,4 linfonodos por paciente e 22,67 quando analisados isoladamente os casos que não receberam tratamento neoadjuvante. Conclusão: a técnica vídeo-tóraco-laparoscópica se mostrou método seguro no tratamento cirúrgico do câncer do esôfago e proporcionou boa amostragem linfonodal em nossa casuística inicial.
\end{abstract}

Descritores: Esofagectomia. Decúbito Ventral. Toracoscopia. Neoplasias Esofágicas.

\section{REFERENCES}

1. Câncer de esôfago. In: Instituto Nacional do Câncer José Alencar Gomes da Silva. Coordenação de Prevenção e Vigilância. Estimativa 2014: incidência de câncer no Brasil. Rio de Janeiro: INCA, 2014. p. 42-3.
2. Smithers BM, Gotley DC, Martin I, Thomas JM. Comparison of the outcomes between open and minimally invasive esophagectomy. Ann Surg. 2007;245(2): 232-40.

3. Pinto CE, Dias JA, Sá EA, Tsunoda AT, Pinheiro RN. Tratamento cirúrgico do câncer de esôfago. Rev Bras Cancerol. 2007;53(4) 425-30. 
4. Palanivelu C, Prakash A, Senthilkumar R, Senthilnathan P, Parthasarathi R, Rajan PS, et al. Minimally invasive esophagectomy: thoracoscopic mobilization of the esophagus and mediastinal lymphadenectomy in prone position- experience of 130 patients. J Am Coll Surg. 2006;203(1):7-16.

5. Feng $M$, Shen $Y$, Wang $H$, Tan $L$, Zhang $Y$, Khan MA, et al. Thoracolaparoscopic esophagectomy: is the prone position a safe alternative to the decubitus position? J Am Coll Surg. 2012;14(5):838-44.

6. Pennathur A, Awais O, Luketich D. Technique of minimally invasive Ivor Lewis esophagectomy. Ann Thorac Surg. 2010;89(6):S2159-62.

7. Yatabe T, Kitagawa H, Yamashita K, Akimori T, Hanazaki K, Yokoyama M. Better postoperative oxygenation in thoracoscopic esophagectomy in prone positioning. J Anesth. 2010;24(5):803-6.

8. NCCN Clinical Practice Guidelines in Oncology. Esophageal and esophagogastric junction cancers (Excluding the proximal $5 \mathrm{~cm}$ of the stomach). Fort Washington: NCCN; 2013.

9. Fabian T, McKelvey AA, Kent MS Frederico JA. Prone thoracoscopic esophageal mobilization for minimally invasive esophagectomy. Surg Endosc 2007;21(9):1667-70.

10. Gossot D, Fourquier P, Celerier M. Thoracoscopic esophagectomy: technique and initial results. Ann Thorac Surg. 1993;56(3):667-70.

11. Dindo D, Demartines N, Clavien PA. Classification of surgical complications: a new proposal with evaluation in a cohort of 6336 patients and results of a survey. Ann Surg. 2004;240(2):205-13.
12. Nguyen N, Hinojosa M, Smith BR, Chang KJ, Gray J, Hoyt D. Minimally invasive esophagectomy: lessons learned from 104 operations. Ann Surg. 2008;248(6):1081-91.

13. Kanaji $S$, Nakamura $T$, Otowa $Y$, Yamamoto $M$, Yamashita K, Imanishi $T$, et al. Thoracoscopic esophagectomy in the prone position for esophageal cancer with right aortic arch: case report. Anticancer Res. 2013;33(10):4515-9.

14. Shapiro J, van Lanschot JJ, Hulshof MC, van Hagen $\mathrm{P}$, van Berge Henegouwen Ml, Wijnhoven BP, van Laarhoven HW, Nieuwenhuijzen GA, Hospers GA, Bonenkamp JJ, Cuesta MA, Blaisse RJ, Busch OR, Ten Kate FJ, Creemers GJ, Punt CJ, Plukker JT, Verheul HM, Bilgen EJ, van Dekken $\mathrm{H}$, van der Sangen MJ, Rozema T, Biermann K, Beukema JC, Piet AH, van Rij CM, Reinders JG, Tilanus HW, Steyerberg EW, van der Gaast A; CROSS study group. Neoadjuvant chemoradiotherapy plus surgery versus surgery alone for oesophageal or junctional cancer (CROSS): long-term results of a randomised controlled trial. Lancet Oncol. 2015;16(9):1090-8.

Received in: 20/03/2017

Accepted for publication: 18/05/2017

Conflict of interest: none.

Source of funding: none.

\section{Mailing address:}

Carlos Bernardo Cola

E-mail: bernardocola@yahoo.com.br 